\title{
Predictors of overall satisfaction of cancer patients undergoing radiation therapy
}

\author{
This article was published in the following Dove Press journal: \\ Patient Preference and Adherence \\ 29 September 2015 \\ Number of times this article has been viewed
}

\author{
Martina Becker-Schiebe ${ }^{1,2}$ \\ Uwe Pinkert' \\ Tahera Ahmad' \\ Christof Schäfer ${ }^{3}$ \\ Wolfgang Hoffmann' \\ Heiko Franz ${ }^{4}$ \\ 'Department of Radiotherapy and \\ Radio-Oncology, Städtisches Klinikum \\ Braunschweig gGmbH, Braunschweig, \\ ${ }^{2}$ Radiation Oncology, Hannover \\ Medical School, Hannover, ${ }^{3}$ Radiation \\ Oncology Straubing, University of \\ Regensburg, Regensburg, ${ }^{4}$ Department \\ of Gynecology and Obstetrics, \\ Städtisches Klinikum Braunschweig \\ gGmbH, Braunschweig, Germany
}

Background: Reporting the experiences and satisfaction of patients, as well as their quality of care scores is an emerging recommendation in health care systems. Many aspects of patients' experience determine their overall satisfaction. The aim of this evaluation was to define the main factors contributing to the satisfaction of patients undergoing radiotherapy in an outpatient setting.

Patients and methods: A total of 1,710 patients with a histologically proven cancer, who were treated in our department between 2012 and 2014, were recruited for this prospective evaluation. At the end of therapy, each patient was asked to grade the skills and the care provided by radiation therapists, physicians, and physician's assistants, as well as the overall satisfaction during therapy. Statistical analysis was performed to determine which parameters had the greatest influence on overall satisfaction.

Results: Overall satisfaction with the provided care was high with a mean satisfaction score of 1.4. Significant correlations were found between overall satisfaction and each of the following survey items: courtesy, protection of privacy, professional skills and care provided by the radiation therapists and physicians, accuracy of provided information, and cleanliness. Linear regression analysis demonstrated that courteous behavior and the protection of privacy were the strongest predictors for overall satisfaction $(P<0.001)$, followed by care and skills of physicians and radiation therapists. Patients suffering from head and neck cancer expressed lower overall satisfaction.

Conclusion: Based on our prospectively acquired data, we were able to identify and confirm key factors for patient satisfaction in an outpatient radiooncological cancer center. From these results, we conclude that patients want most importantly to be treated with courtesy, protection of privacy and care.

Keywords: patient satisfaction, radiotherapy, information

\section{Introduction}

Patient satisfaction is a commonly analyzed parameter when evaluating medical treatments and institutions. Reporting the experiences and satisfaction of patients, as well as their quality of care scores, is an emerging recommendation in health care systems, especially for the accreditation of cancer centers. ${ }^{1}$ Evaluation of such parameters helps in assessing the performance of the department and thus recognizes deficits and measures required for improvement.

Many aspects of patients' experiences determine their overall satisfaction. A variety of studies ${ }^{2-6}$ have in particular focused on the satisfaction of oncology patients. The experience of patients during therapy has been shown to be associated with patient-related social and emotional aspects as well as with a caring attitude by physicians. ${ }^{2,7}$ Some studies have demonstrated that an enhancement of communication between the medical staff and the patient may improve patient satisfaction as well. ${ }^{1}$ 
In 2008 Famiglietti et $\mathrm{al}^{8}$ found that in radiation oncology settings, the assessment made by patients of their relationship with the medical staff was the greatest contributor to overall satisfaction. Conflicting results, however, have been reported for other factors such as environmental issues, waiting time, and educational information, and the relationship between self-perceived quality of life (QOL) and satisfaction with care remains a subject of debate. ${ }^{1,9}$

Some studies have reported that radiotherapy, more so than other oncological treatments, may be linked to lower satisfaction scores due to possible delays until a definitive treatment can be delivered, difficulties in scheduling appointments, and fears about the correct delivery of the treatment. ${ }^{1}$ Lower satisfaction scores may reduce patient compliance and thereby impede completion of therapy protocols and effective treatment of the cancer. Furthermore, this may lead to a deterioration of patient QOL.

Several validated and reliable questionnaires for the assessment of patient satisfaction have been published. ${ }^{4,5,10}$ In accordance with these, a satisfaction questionnaire was devised assessing different specific aspects of patient care, communication, and environment of the institution providing the treatment.

There is evidence that primary tumor localization is a variable significantly associated with satisfaction in ambulatory oncology patients, ${ }^{1}$ but only a very few studies have focused on disease-specific satisfaction scores of radiation oncology patients.

The aim of this evaluation was to define the main factors contributing to the satisfaction of patients undergoing radiotherapy in an outpatient setting. In addition, we sought to determine whether patient satisfaction differed for different disease entities.

\section{Patients and methods}

All patients with a histologically proven primary or metastatic cancer who were treated by radiation therapy in our department between 2012 and 2014 were recruited for a prospective evaluation of their levels of satisfaction.

All patients were accrued at the beginning of treatment. At the end of the radiation therapy, patients were asked to grade their satisfaction during the therapy. Inclusion criteria were an age of $>18$ years and the capability to complete the questionnaires. Assessment was performed at a single radiotherapy cancer center.

Patients were asked to give a continuous ranking, ranging from 1 to 4 (with 1 indicating very good and 4 indicating bad) to 14 different aspects of their treatment. The $1-4$ ranking was validated by a German study dealing with satisfaction with inpatient management. ${ }^{11}$ A standardized questionnaire according to the European Organisation for Research and Treatment of Cancer (EORTC) SAT 32 subscales was administered to our cancer outpatients using the EvaSys program, ${ }^{1,12}$ but for our survey the questionnaire was modified to facilitate data collection. The questionnaires had to be filled in directly by the patients without help from the medical staff.

The items (ie, aspects of the treatment) surveyed included the skills (ie, knowledge and experience, and assessment of physical symptoms) and the care (ie, willingness to listen, availability, and interest) provided by the radiation therapists, physicians, and physicians' assistants. Additional items included waiting time, scheduling of the therapy session, clarity of explanations and information about the treatment procedure and side effects, courtesy of the representatives of each discipline, protection of privacy and personal interests, and the environment of the treatment institution (eg, seating, cleanliness, location information, and availability of newspapers during the waiting time). The clinical parameters included age, sex, and disease entity. Apart from this, patients were asked to weigh the subjective importance of the domains appointment scheduling, courtesy, professional skills, and services. Personal remarks could be added voluntarily.

Responses were received from 1,710 patients, yielding a response rate of $45 \%$.

Graphical and descriptive analyses were carried out with the program EvaSys X (Electric Paper Evaluationssysteme GmbH, Lüneburg, Germany). The statistical evaluation of the data was carried out using descriptive statistical methods in the SPSS software package (Windows) and the Real Statistics Data Analysis ToolTM/Excel/Microsoft Word.

For the simple comparison of satisfaction scores for each item surveyed, mean values were calculated. The different variables were evaluated in contingency tables. Associations between each survey question and the overall satisfaction score were calculated using chi-square tests, and continuous variables were analyzed by applying Fisher's exact test. First, bivariate correlation coefficients were calculated comparing each survey item with the overall satisfaction score. Then, a linear regression analysis was performed to determine which parameters had the greatest influence on overall satisfaction. For this analysis, the dependent variable was the overall satisfaction score and the independent variables were the scores of the different survey items. The results are presented as the values of the means of regression coefficients $\beta$ and $P$. The satisfaction scores were converted to the main categoric 
variables for full approval (score 1), very good (1-1.4), good (1.5-2.4), satisfactory (2.5-3.4), bad (3.5-4), and full disapproval (score 4), and frequencies were calculated.

In addition, correlations were calculated for full approval (score 1) or full disapproval (score 4) and overall satisfaction depending on age, sex, and origin of the cancer. $P$-value $<0.05$ was considered as statistically significant. Patient names were not associated with the questionnaire. The analysis of this survey was performed in accordance with ethical standards.

\section{Results}

A total of 1,710 questionnaires were evaluated in our prospective study of patient satisfaction conducted between 2012 and 2014. The mean age was 63.5 years, and three patients failed to answer the questions about age. Female patients made up $59 \%$ of the study cohort. The distribution of the primary cancer sites and the complete patient baseline characteristics are shown in Table 1; note that $36 \%$ of the patients were treated for breast cancer.

Frequencies of complete approval, very good and good satisfaction scores are shown in Table 2, none of the patients reported complete disapproval except concerning the item "availability of newspapers during the waiting time".

Overall satisfaction with the provided care was high, with a mean satisfaction score of 1.4 (in a range of $1-4$, where a score of 1 indicates the highest level of satisfaction).

The association between each survey question and the overall satisfaction score is shown in Table 2. Significant correlations were found between overall satisfaction and each of the following survey items: courtesy, protection of privacy,

Table I Patients baseline of the study cohort

\begin{tabular}{ll}
\hline Characteristics & $\begin{array}{l}\text { Number of patients (\%)/ } \\
\text { mean value }\end{array}$ \\
\hline $\begin{array}{l}\text { Sex }(\mathrm{n}=|, 7| 0) \\
\text { Female }\end{array}$ & $1,015(59 \%)$ \\
Male & $695(41 \%)$ \\
Age ( $=I, 707)$ & 63.5 years \\
& $(21-89$ years $)$ \\
$<45$ years & $296(17 \%)$ \\
$<46-70$ years & $925(54 \%)$ \\
$>7 I$ years & $486(28 \%)$ \\
Disease entity ( $=I, 7 I 0)$ & \\
Breast cancer & $617(36 \%)$ \\
Gynecological cancer & $40(2 \%)$ \\
Prostate cancer & $217(13 \%)$ \\
Gastrointestinal cancer & $193(11 \%)$ \\
Lung cancer & $74(4 \%)$ \\
Head and neck & $121(7 \%)$ \\
Other or metastatic disease & $448(26 \%)$ \\
\hline
\end{tabular}

and professional skills and care provided by the radiation therapists and physicians. Furthermore, an association between the overall satisfaction and accuracy of provided information as well as cleanliness were also observed. To more accurately assess which items had the largest effects on overall satisfaction, a multivariate analysis was performed (Table 3). A linear regression analysis demonstrated that courteous behavior by radiation therapists and physicians and the protection of privacy were the strongest predictors of the overall satisfaction score $(P<0.001)$, followed by the care and skills of the physicians and radiation therapists, and then cleanliness.

Regarding daily appointment scheduling and the environment of the treatment center (except cleanliness), no significant associations with the overall satisfaction score were identified $(P>0.05)$.

Overall patient satisfaction did not vary with cancer type, except for patients suffering from head and neck cancer who expressed lower overall satisfaction, with an overall mean satisfaction score of 1.8 (standard deviation [SD] 0.4, $P=0.049$ ) (Table 4). In particular, these patients expressed significantly lower satisfaction regarding information about therapy and side effects, care and skills of the radiation therapists, and protection of privacy by physicians/ radiation therapists than did the entire study group $(P<0.05$, Table 4 and Figure 1).

There were no significant age- or sex-dependent differences in the overall satisfaction score. The mean satisfaction scores of patients $<45$ years, age $46-70$ years, and $>71$ years were 1.6/0.6 SD, 1.4/0.6 SD, and 1.4/0.5 $\mathrm{SD}$, respectively. Patients older than 71 years were slightly more satisfied (ie, by mean scores of 0.2 ) with the accuracy of information about therapy, care and professional skills of the medical staff, and protection of privacy than were the other patients.

The ranking of subjective importance of the different domains by the entire patient cohort did not reveal any significant differences. Scores for appointment scheduling, courtesy, professional skills, and services for scheduling were 1.4/0.4 SD, 1.2/0.4 SD, 1.3/0.4 SD, and 1.5/0.5 SD, respectively $(P>0.05)$.

Subgroup analysis based on sex revealed a trend toward greater importance of appointment scheduling and lower importance of overall courtesy for female patients (Figure 2). No other associations in this subgroup analysis were detected.

A comparison of the responses to specific survey items given by patients who gave an overall satisfaction score 
Table 2 Associations between each survey question and the overall satisfaction score

\begin{tabular}{|c|c|c|c|c|c|}
\hline \multirow[t]{2}{*}{ Question } & \multicolumn{2}{|c|}{ Satisfaction score } & \multirow{2}{*}{$\begin{array}{l}\text { Correlation with overall } \\
\text { satisfaction }(P \text {-value) }\end{array}$} & \multirow{2}{*}{$\begin{array}{l}\text { Complete } \\
\text { approval (\%) }\end{array}$} & \multirow{2}{*}{$\begin{array}{l}\text { Very good and good } \\
\text { satisfaction scores (\%) }\end{array}$} \\
\hline & Mean & SD & & & \\
\hline Overall satisfaction & 1.4 & 0.6 & & 88.5 & 98.4 \\
\hline Waiting time/appointment scheduling & 1.7 & 0.7 & 0.11 & 44.1 & 88.1 \\
\hline $\begin{array}{l}\text { Accuracy of information about therapy, } \\
\text { explanation about side effects }\end{array}$ & 1.4 & 0.6 & 0.033 & 62.2 & 97.8 \\
\hline \multicolumn{6}{|l|}{ Courteous behavior of } \\
\hline Physicians & 1.3 & 0.5 & 0.02 & 75.1 & 99.4 \\
\hline Radiation therapist & 1.1 & 0.4 & $<0.001$ & 90.1 & 100 \\
\hline Receptionists & 2.1 & 0.9 & 0.71 & 65.1 & 75.3 \\
\hline \multicolumn{6}{|l|}{ Care and professional skills provided by } \\
\hline Physicians & 1.4 & 0.6 & 0.033 & 60.2 & 97.8 \\
\hline Radiation therapist & 1.5 & 0.6 & 0.038 & 51.1 & 91.4 \\
\hline \multicolumn{6}{|c|}{ Protection of privacy and personal interests } \\
\hline Physicians & 1.3 & 0.5 & 0.031 & 72.2 & 99.1 \\
\hline Radiation therapist & 1.2 & 0.5 & $<0.001$ & 79.6 & 100 \\
\hline \multicolumn{6}{|l|}{ Environment of the treatment institution } \\
\hline Seating & 1.7 & 0.9 & 0.09 & 40.0 & 85.3 \\
\hline Location information & 1.7 & 0.7 & 0.09 & 38.9 & 87.1 \\
\hline $\begin{array}{l}\text { Availability of newspapers during the } \\
\text { waiting time }\end{array}$ & 2.5 & 0.9 & 0.21 & 24.1 & 52.7 \\
\hline Cleanliness & 1.6 & 0.6 & 0.048 & 50.0 & 88.8 \\
\hline
\end{tabular}

Abbreviation: SD, standard deviation.

of 1 versus those giving an overall satisfaction score of $\geq 1$ was performed to determine which survey question had the greatest influence on full approval. This comparison showed that the care, skills, and protection of privacy provided by the physicians as well as information about the therapy and the explanation of the side effects were large contributors toward the highest overall satisfaction $(P=0.035)$. The other survey items were similar between these patient groups (Figure 3).

\section{Discussion}

Over the last few years, patient-reported assessment of the outcomes of their medical procedures, QOL assessments, and

Table 3 Linear regression analysis: significant predictors for the overall satisfaction score

\begin{tabular}{|c|c|c|c|}
\hline Item & $R^{2}$ & $\beta(95 \% \mathrm{Cl})$ & $P$-value \\
\hline $\begin{array}{l}\text { Courteous behavior of radiation } \\
\text { therapists }\end{array}$ & 0.66 & 0.003 & $<0.00$ I \\
\hline Courteous behavior of physicians & & 0.004 & $<0.001$ \\
\hline $\begin{array}{l}\text { Protection of privacy (entire } \\
\text { personal staff) }\end{array}$ & & 0.06 & $<0.001$ \\
\hline Care and skills of physicians & & 0.17 & 0.03 \\
\hline $\begin{array}{l}\text { Care and skills of radiation } \\
\text { therapists }\end{array}$ & & 0.18 & 0.031 \\
\hline Information about therapy & & 0.31 & 0.04 \\
\hline Cleanliness & & 0.32 & 0.035 \\
\hline
\end{tabular}

Abbreviations: $\beta$, regression coefficient; $\mathrm{Cl}$, confidence interval. overall satisfaction scores have been recognized as important criteria to evaluate and to compare medical treatments. A review of the relevant literature, however, has revealed little consistency regarding clinical and demographic determinants of patient satisfaction. ${ }^{5}$ Most of the studies included cancer patients receiving treatment on the ward. Cancer patients have a particularly high risk of emotional imbalance and disorders due to the anxiety and distress caused by the diagnosis, its prognosis, and the required treatment procedures. ${ }^{6,13}$ This emotional stress can be amplified by a lack of information, and by dissatisfaction with the care and skills of the clinical staff. Therefore, monitoring patient satisfaction during complex cancer treatments is essential to enhance patient compliance and thereby ensuring an effective treatment of the cancer. ${ }^{6}$

Table 4 Overall satisfaction scores for different cancer origins

\begin{tabular}{lll}
\hline Disease entity & $\begin{array}{l}\text { Satisfaction score } \\
\text { (mean) }\end{array}$ & SD \\
\hline Prostate cancer & 1.4 & 0.5 \\
Breast cancer & 1.4 & 0.6 \\
Gynecological cancer & 1.4 & 0.6 \\
Gastrointestinal cancer & 1.4 & 0.6 \\
Lung cancer & 1.4 & 0.6 \\
Head and neck cancer & 1.8 & $0.4(P=0.049)$ \\
\hline
\end{tabular}

Abbreviation: SD, standard deviation. 


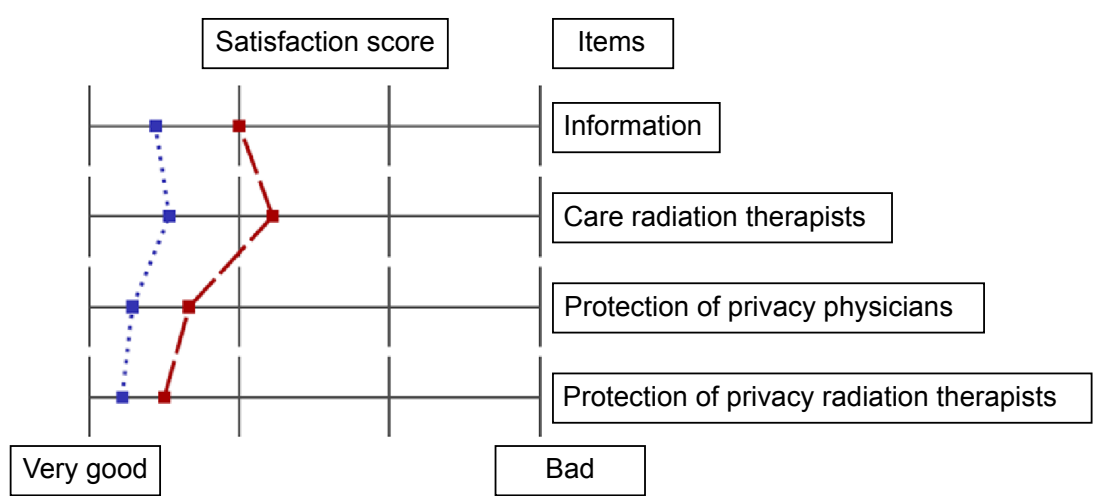

$$
\begin{array}{ll}
\mathrm{mw}=2.0 \mathrm{md}=2.0 \mathrm{~s}=0.0 & \mathrm{H} \& \mathrm{~N} \\
\mathrm{mw}=1.4 \mathrm{md}=1.0 \mathrm{~s}=0.6 & \text { All patients } \\
\mathrm{mw}=2.2 \mathrm{md}=2.0 \mathrm{~s}=0.4 & \mathrm{H} \& \mathrm{~N} \\
\mathrm{mw}=1.5 \mathrm{md}=1.0 \mathrm{~s}=0.6 & \text { All patients } \\
\mathrm{mw}=1.7 \mathrm{md}=2.0 \mathrm{~s}=0.5 & \mathrm{H} \& \mathrm{~N} \\
\mathrm{mw}=1.3 \mathrm{md}=1.0 \mathrm{~s}=0.5 & \text { All patients } \\
\mathrm{mw}=1.5 \mathrm{md}=1.5 \mathrm{~s}=0.5 & \mathrm{H} \& \mathrm{~N} \\
\mathrm{mw}=1.2 \mathrm{md}=1.0 \mathrm{~s}=0.5 & \text { All patients }
\end{array}
$$

Figure I Differences in answers to survey questions between head and neck cancer (H\&N) patients (---) and all patients (...).

Notes: Patient satisfaction with information, care and skills of the radiation therapists, and protection of privacy by physicians/radiation therapists were significantly different between the H\&N patients and the entire study group $(P<0.05)$.

Abbreviations: $\mathrm{mw}$, mean value; $\mathrm{md}$, median value; $\mathrm{s}$, standard deviation.

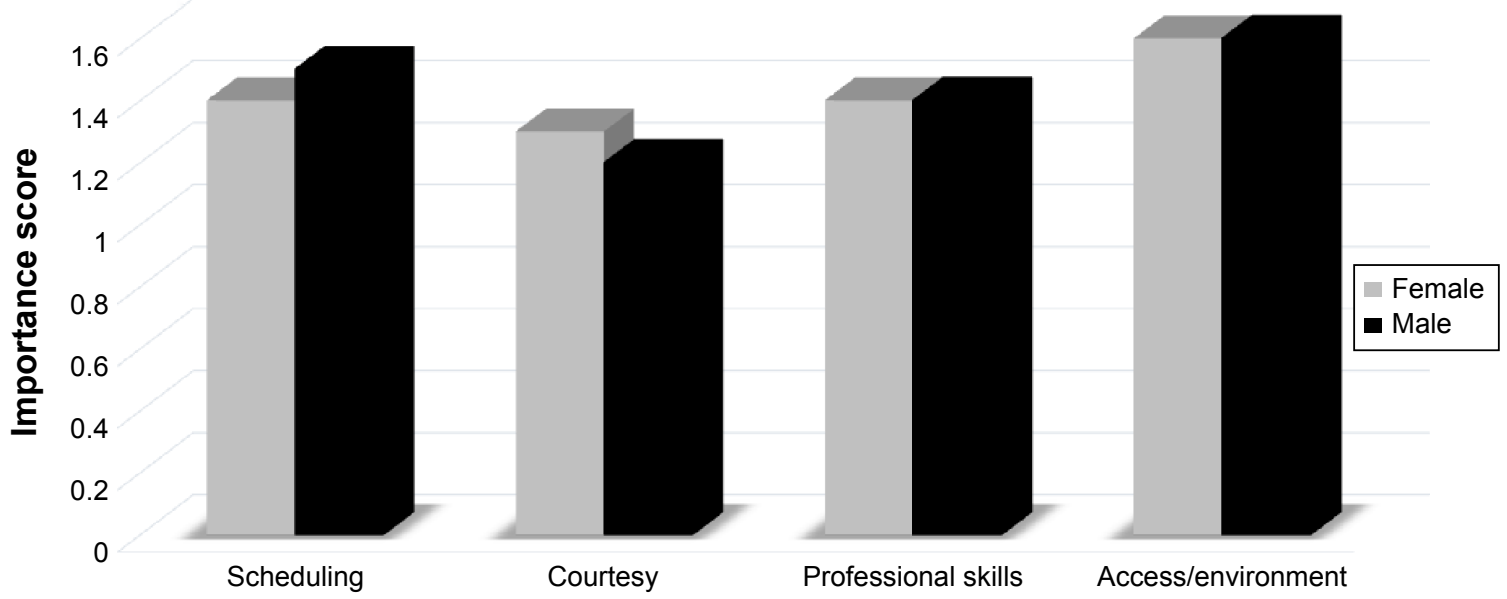

Figure 2 The dependence of the subjective evaluation of major health care components on sex was not significant $(P>0.05)$, although appointment scheduling was a bit more important and overall courtesy was a bit less important for female patients than for male patients.

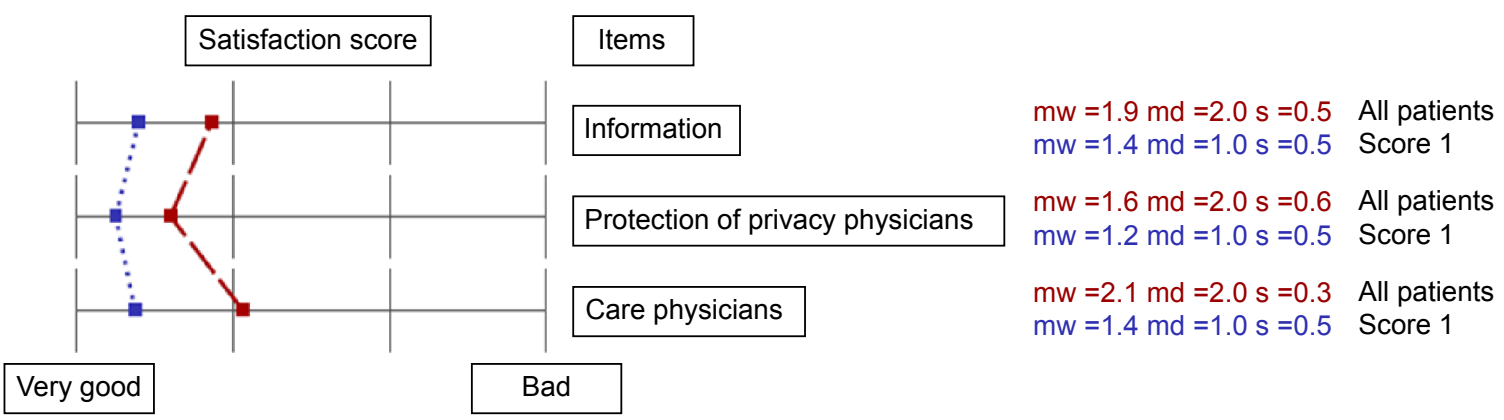

Figure 3 Comparison of the responses to selected survey items for all patients whose overall satisfaction score is I (...) versus those for all patients whose overall satisfaction score $\geq I(--)(P<0.05)$.

Abbreviations: $\mathrm{mw}$, mean value; $\mathrm{md}$, median value; $\mathrm{s}$, standard deviation. 
There has only been a small amount of information published to date regarding determinants of patient satisfaction specific to radiooncologic outpatients. Several of the studies were based on retrospective case series or random sampling designs. ${ }^{4,5,7,14}$

The characteristics of our prospectively evaluated study population (Table 1) were comparable to those of published data $^{15}$ and represented the typical distribution of cancer diseases in an outpatient radiooncological department.

In our analysis of 1,710 patients, the overall satisfaction with care was high, with a mean satisfaction score of 1.4 (based on a range of $1-4$, with a score of 1 being the highest).

These data compare well with data from the study of Geinitz et a $\mathrm{l}^{15}$ who also demonstrated high satisfaction scores ( $94.9 \%-98.8 \%$ on a $0 \%-100 \%$ scale) for 273 cancer patients. In their trial, most patients were irradiated for breast and urogenital cancers without any disease-specific differences, and the analysis was performed only during the 1 st week of therapy.

Nguyen et al ${ }^{1}$ did, however, observe satisfaction scores in ambulatory oncology patients to be dependent on the type of therapy they received: patients treated by chemoradiation reported significantly lower levels of satisfaction, by a mean score difference of $>10$ on a $0 \%-100 \%$ scale, for provision of information than did patients treated by chemotherapy only. It was also postulated that a higher proportion of radiotherapy patients were dissatisfied with the accuracy of the information about the more complex care pathways for the preparation and scheduling of radiation treatment. Another analysis of 210 oncology patients examined the effect that the provision of treatment information had on patient satisfaction, and these data supported the importance of delivering adequate explanations about the side effects that could be expected from the treatment. ${ }^{16}$ A review of the literature showed several studies based on different types of cancer for inpatient and outpatient cohorts in different treatments settings. ${ }^{1,8,9,15-18}$ In summary, the items for which patients expressed concern most often were information about the therapy and the course of therapy. ${ }^{19,20}$

The study of Geinitz et al ${ }^{15}$ mentioned above specifically evaluated satisfaction of both inpatients and outpatients receiving radiotherapy. Their subanalysis demonstrated that the most wanted additional information, specifically in $65 \%$ of the cases, included technical aspects of X-rays and the function of the linear accelerators. Information was less often requested concerning side effects ( $45 \%$ of the patients). In this study, patients wished to receive information mostly via brochures and directly via their oncologist. Interestingly, the data confirmed that patients expressing information seeking behaviors stated that the first communication with the oncologist did increase their anxiety. Targeted additional information or patient orientation programs might help patients to obtain additional information., ${ }^{2,6,10,15}$

In our study, a significant correlation between "information about therapy and side effects" and overall satisfaction score was shown, but this survey item was not the strongest determinant for overall satisfaction. Furthermore, we confirmed the significant importance of "information", "protection of privacy", and "care provided by physicians" for the subgroup of patients who showed full approval (ie, overall satisfaction score $=1$, Figure 3).

Although the weighting of the subjective importance of "scheduling", "courtesy", "professional skills", and "services" was comparable for the entire patient cohort and subgroups (Figure 2), we were able to rank the items most strongly correlated with the overall satisfaction score and also found significant differences between subgroups (Tables 2 and 3, Figure 1).

The strongest predictors for overall satisfaction were courteous behavior of the radiation therapists and physicians and protection of patients' privacy, followed by the care provided by the medical staff and the skills of the physicians and radiation therapists, as well as information and cleanliness (Table 3).

Observations similar to those of our study have also been described for other types of patients. A study evaluating gynecological patients ${ }^{13}$ confirmed that evaluation of care is closely related to the interpersonal aspects of the health care provider, especially their courteous behavior and personal care.

In two EORTC studies, patient satisfaction of surgical patient cohorts was assessed; as for our data, both of these studies found that the key factors for satisfaction were personal care provided by physicians and nurses..$^{21,22}$

Some studies have tried to identify factors for overall patient satisfaction associated with diagnosis and QOL but the relationship between QOL and overall patient satisfaction remains unclear. ${ }^{18,23}$ Contradictory data have been published evaluating functional symptom scales and QOL ranking. Avery et $\mathrm{al}^{21}$ reported how patient satisfaction was related to surgical morbidity. Patients who experienced major morbidity complained of a significantly lower QOL but indicated comparable satisfaction scores. Apart from this, a cross-sectional French study ${ }^{1}$ confirmed poor overall health status and the diagnosis of head and neck cancer as the main determinants of low levels of satisfaction. 
In our analysis, the diagnosis of head and neck cancer was the single disease-specific parameter for lower overall satisfaction compared with other disease entities. The majority of our head and neck cancer patients were treated by definitive radiochemo- and/or immunotherapy. These patients frequently experience pain, dysphagia, and severe radiomucositis and radiodermatitis, which lead to functional problems and difficulties in communication. Our subgroup analysis also confirmed a lower satisfaction of head and neck cancer patients for the item "information" (Figure 1).

Interestingly, we could not identify any differences concerning satisfaction between breast and prostate cancer patients for our outpatient cohort. The data published by Sherlaw-Johnson et $\mathrm{a}^{24}$ for an inpatient study group described better satisfaction scores for breast cancer patients compared with prostate cancer patients. Note that these authors also described greater dissatisfaction for younger patients. We could not identify significant age-dependent differences but a trend toward a better evaluation by patients older than 71 years was shown.

We are aware of the obvious limitations of our study, including an overall response rate of only $45 \%$, and we are therefore missing the opinions of the non-responders. While it is possible that our study is not fully representative of all patients seen, the baseline characteristics of our study population was comparable to published data. ${ }^{15}$ In addition, we used a survey with a reduced number of questions to improve patient compliance for study participation. Nevertheless, the main items of the validated EORTC survey ${ }^{12}$ were analyzed. Since the study of Nguyen et $\mathrm{al}^{1}$ demonstrated that the level of education was not associated with satisfaction scores, we did not include information on education, although other reports have revealed contradictory results in this regard. The lack of information concerning the socioeconomic status of patients might be a possible confounder, and we were not able to further consider whether this could have affected overall satisfaction scores.

\section{Conclusion}

There has only been little information to date regarding determinants of patient satisfaction specific to radiooncological patients in an outpatient setting. Based on our prospectively acquired data of more than 1,700 patients, we were able to identify and confirm key factors for patient satisfaction in an ambulatory, radiooncological cancer center. From these results, we conclude that patients want most importantly to be treated with courtesy, protection of privacy, care, and empathy. Expectations of care are high especially for patients undergoing radiation $+/-$ chemotherapy lasting over several weeks. Radiation therapists should be aware that the accuracy of adequate information supplied to the patient about the treatment and related toxicities are essential for patient satisfaction and compliance, and hence effective cancer treatment.

\section{Disclosure}

The authors report no conflicts of interest in this work.

\section{References}

1. Nguyen T, Bosset J, Monnier A, et al. Determinants of patient satisfaction in ambulatory oncology: a cross sectional study based on the OUT-PATSAT35 questionnaire. BMC Cancer. 2011;11:526-537.

2. Brix C, Schleussner C, Füller J, Roehrig B, Wendt TG, Strauss B. The need for psychosocial support and its determinants in a sample of patients undergoing radiooncological treatment of cancer. J Psychosom Res. 2008;65:541-548.

3. Brix C, Schleußner C, Füller J, et al. [Fatigue und deren Determinanten in der Radioonkologie]. Psychother Psychosom Med Psychol. 2009; 59:42-49.

4. Kamo N, Dandapani SV, Miksad RA, et al. Evaluation of the SCA instrument for measuring patient satisfaction with cancer care administered via paper or via the Internet. Ann Oncol. 2011;22:723-729.

5. Like R, Zyzanski SJ. Patient satisfaction with the clinical encounter: social psychological determinants. Soc Sci Med. 1987;24:351-357.

6. Sehlen S, Hollenhorst H, Schymura B, et al. Psychosocial stress in cancer patients during and after radiotherapy. Strahlenther Onkol. 2003; 179:175-180.

7. Avis M, Bond M, Arthur A. Questioning patient satisfaction: an empirical investigation in two outpatient clinics. Soc Sci Med. 1997;44:85-92.

8. Famiglietti RM, Neal EC, Edwards TJ, et al. Determinants of patient satisfaction during receipt of radiation therapy. Int J Radiat Oncol Biol Phys. 2013;87(1):148-152.

9. Westaway M, Rheeder P, Van Zyl D, et al. Interpersonal and organizational dimensions of patient satisfaction: the moderating effects of health status. Int J Qual Health Care. 2003;15:337-344.

10. Henrich G, Herschbach P, Schäfer I. Fragen zur Patientenzufriedenheit (FPZ) - Die Entwicklung eines Fragebogens. Z Med Psychol. 2001; 10:147-158.

11. Schmidt J, Lamprecht F, Wittmann WW. Satisfaction with inpatient management. Development of a questionnaire and initial validity studies. Psychother Psychosom Med Psychol. 1989;39:248-255.

12. Bredart A, Mignot V, Rousseau A, et al. Validation of the EORTC QLQ-SAT32 cancer inpatient satisfaction questionnaire by selfversus interview-assessment comparison. Patient Educ Couns. 2004; 54:207-212.

13. Von Gruenigen V, Hutchins J, Reidy A, et al. Gynecologic oncology patients' satisfaction and symptom severity during palliative chemotherapy. Health Qual Life Outcomes. 2006;4:84.

14. Bhatnagar AK, Land SR, Shogan A, et al. What do patients want from their radiation oncologist? Initial results from a prospective trial. Int $J$ Radiat Oncol Biol Phys. 2007;69:1527-1533.

15. Geinitz H, Marten-Mittag B, Schäfer C, et al. Patient satisfaction during radiation therapy. Correlates and patient suggestions. Strahlenther Onkol. 2012;188:492-498.

16. Haggmark C, Bohman L, Ilmoni-Brandt K, et al. Effects on information supply on satisfaction with information and quality of life in cancer patients receiving curative radiation therapy. Patient Educ Couns. 2001; 45:173-179.

17. Takahashi T, Hondo M, Nishimura K, et al. Evaluation of quality of life and psychological response in cancer patients treated with radiotherapy. Radiat Med. 2008;26:396-401.

18. Wensing M, Grol R, Asberg J, et al. Does health status of chronically ill patients predict their judgement of the quality of general practice care? Qual Life Res. 1997;6:293-299. 
19. Adler J, Paelecke-Habermann Y, Jahn P, et al. Patient information in radiation oncology. Radiat Oncol. 2009;4:40.

20. Davidson R, Mills M. Cancer patients' satisfaction with communication, information and quality of care in a UK region. Eur J Cancer Care. 2005; 14:83-90.

21. Avery K, Metcalfe C, Nicklin J, et al. Satisfaction with care: an independent outcome measure in surgical oncology. Ann Surg Oncol. 2006;13: $817-822$.

22. Kavadas V, Barham C, Finch-Jones M, et al. Assessment of satisfaction with care after inpatient treatment for esophageal and gastric cancer. Br J Surg. 2004;91:719-723.
23. Shelby RA, Golden-Kreutz DM, Andersen BL. PTSD diagnoses, subsyndromal symptoms and comorbidities contribute to impairments for breast cancer survivors. J Trauma Stress. 2008;21:165-172.

24. Sherlaw-Johnson C, Datta P, McCarthy M, et al. Hospital differences in patient satisfaction with care for breast, colorectal, lung and prostate cancers. Eur J Cancer. 2008;44:1559-1565.

\section{Publish your work in this journal}

Patient Preference and Adherence is an international, peer-reviewed, open access journal that focuses on the growing importance of patient preference and adherence throughout the therapeutic continuum. Patient satisfaction, acceptability, quality of life, compliance, persistence and their role in developing new therapeutic modalities and compounds to optimize clinical outcomes for existing disease states are major areas of interest for the journal. This journal has been accepted for indexing on PubMed Central. The manuscript management system is completely online and includes a very quick and fair peer-review system, which is all easy to use. Visit http://www. dovepress.com/testimonials.php to read real quotes from published authors.

Submit your manuscript here: http://www.dovepress.com/patient-preference-and-adherence-journal 